Article

\title{
Regulation of Morphology, Aflatoxin Production, and Virulence of Aspergillus flavus by the Major Nitrogen Regulatory Gene areA
}

\author{
Opemipo Esther Fasoyin ${ }^{1,2, \dagger}{ }^{\dagger}$ Kunlong Yang ${ }^{3, \dagger}$, Mengguang Qiu ${ }^{1}$, Bin Wang ${ }^{1}$, Sen Wang ${ }^{1}$ \\ and Shihua Wang ${ }^{1, *}$ \\ 1 Key Laboratory of Pathogenic Fungi and Mycotoxins of Fujian Province, Key Laboratory of Biopesticide \\ and Chemical Biology of Education Ministry, and School of Life Sciences, Fujian Agriculture and Forestry \\ University, Fuzhou 350002, China; 2018Y90100114@caas.cn (O.E.F.); 1140517012@fafu.edu.cn (M.Q.); \\ 000q120011@fafu.edu.cn (B.W.); 2170517007@fafu.edu.cn (S.W.) \\ 2 Biotechnology Research Institute, Chinese Academy of Agricultural Sciences, Beijing 100081, China \\ 3 School of Life Science, Jiangsu Normal University, Xuzhou 221116, Jiangsu, China; ykl_long@jsnu.edu.cn \\ * Correspondence: wshmail@m.fafu.edu.cn \\ + These authors contributed equally to this work.
}

Received: 7 October 2019; Accepted: 26 November 2019; Published: 10 December 2019

check for updates

\begin{abstract}
Aspergillus flavus is a renowned plant, animal and human pathogen. areA is a global nitrogen regulatory gene of the GATA transcription factor family, shown to be the major nitrogen regulator. In this study, we identified are $A$ in $A$. flavus and studied its function. The AreA protein contained a signatory zinc finger domain, which is extremely conserved across fungal species. Gene deletion $(\triangle \operatorname{are} A)$ and over-expression $(\mathrm{OE}::$ are $A)$ strains were constructed by homologous recombination to elucidate the role of are $A$ in $A$. flavus. The $\triangle$ are A strain was unable to efficiently utilize secondary nitrogen sources for growth of $A$. flavus, and it had poorly developed conidiophores, when observed on complete medium, resulting in the production of significantly less conidia than the wild-type strain (WT). Aflatoxin B1 (AFB1) production was reduced in $\triangle$ are A compared with the WT strain in most conditions tested, and $\triangle a r e A$ had impaired virulence in peanut seeds. are $A$ also played important roles in the sensitivity of $A$. flavus to osmotic, cell wall and oxidative stresses. Hence, are $A$ was found to be important for the growth, aflatoxin production and pathogenicity of $A$. flavus. This work sheds light on the function of are $A$ in the regulation of the nitrogen metabolism of $A$. flavus, and consequently aims at providing new ways for controlling the crossover pathogen, A. flavus.
\end{abstract}

Keywords: Aspergillus flavus; aflatoxins; nitrogen metabolism; glutamine; AreA

Key Contribution: The GATA transcription factor and major nitrogen regulator AreA, was shown to regulate nitrogen metabolism and aflatoxin B1 production in A. flavus.

\section{Introduction}

Aspergillus flavus is a pathogenic soil-borne saprophyte and filamentous fungus which is widely known for its colonization and infection of many important agricultural crops such as cereal grains, tree nuts and legumes in the field, as well as during storage and/or transport [1-5]. A. flavus can exploit a wide range of naturally derived nutrient sources, ranging from economic crops and bodies of dead animals to humans and animals with compromised immune systems [5-9], and it produces various secondary metabolites such as the toxic compounds called mycotoxins. The consumption of these compounds is toxic to mammals, with effects ranging from immunosuppression to death in humans [10]. 
Fungi have the ability to utilize diverse compounds as nitrogen sources. The expression of genes encoding the enzymes and permeases required for nitrogen utilization is regulated by a general mechanism known as nitrogen metabolite repression, which makes them highly expressed in nitrogen-limited and starvation conditions. This allows the preferred use of nitrogen sources that can easily be incorporated as nutrients, such as ammonium and glutamine [11]. Han and colleagues previously reported that glutamine is a preferred nitrogen source in the aflatoxin production of $A$. flavus, with $4 \mathrm{mM}$ limiting threshold concentration [12]. AreA, a highly conserved GATA transcription factor, is the major nitrogen regulatory protein, known for its function of furnishing organisms with the ability to exploit various secondary nitrogen sources. The function of this protein and its homologues have been widely studied in various fungi [13-18]. AreA contains a zinc finger domain, with a central loop which plays an important role in the affinity of DNA binding. The L7 (Leucine) residue in the central loop of AreA is reported to be involved in the distinction of recognition elements present in gene promoters [19]. Glutamine and ammonia have been found to inhibit the activity of AreA and NIT2 in Aspergillus nidulans and Neurospora crassa, respectively, and the presence of excess or free glutamine in the cell triggers NmrA, another protein in the nitrogen metabolism pathway to form a complex with AreA, thereby inhibiting its DNA-binding activity [20-22]. In A. flavus, the lack of $n m r A$ induced a higher transcript level of are $A$ in comparison with the wild-type strain [23]. Gln3p, a global regulator in Saccharomyces cerevisiae, participating in the expression of diverse genes associated with nitrogen metabolism, was shown to be rapidly dephosphorylated and accumulated in the nucleus as a result of nitrogen starvation and rapamycin addition $[24,25]$. AreA, its homolog in A. nidulans, however, was accumulated in the nucleus only in the absence of preferable nitrogen sources [26,27].

AreA is not only involved in the regulation of nitrogen metabolism, but it also plays certain roles in the secondary metabolite biosynthesis and virulence of pathogens. In Acremonium chrysogenum, the deletion of AcareA resulted in the loss of the derepression of nitrogen metabolism and decreased the production of cephalosporin [28]. Studies on Fusarium graminearum showed that the vegetative growth, nitrogen metabolism, pathogenicity and deoxynivalenol production of the AreA/NIT2 ortholog mutant were significantly affected [29]. NRE, the AreA/NIT2 ortholog in Penicillium chrysogenum plays a role in its nitrogen metabolism, and may also regulate penicillin biosynthesis $[15,30]$. In Fusarium verticillioides, fumonisin production is controlled by AREA [31]. Likewise, gibberellin biosynthesis in Fusarium fujikuroi is strictly mediated by AREA [14,18,32,33]. The deletion of areA in Colletotrichum gloeospoiodes results in a significant decrease in vegetative growth and pathogenicity, but increased sporulation [34]. Generally, the major nitrogen regulator, AreA/NIT2, is associated with nitrogen metabolism in a lot of plant pathogenic fungi, but it functions differently and in complicated manners in the pathogenicity of various species. Hence, the need for the investigation of the role of AreA in the plant, animal, and human pathogen $A$. flavus.

In this study, we identified the major nitrogen regulatory gene are $A$ in $A$. flavus, encoding a transcription factor made up of 866 amino acids. Although are $A$ homologues have been widely studied in fungi, nothing is known of its effect on the morphology, secondary metabolite biosynthesis and virulence of $A$. flavus.

\section{Results}

\subsection{Identification of AreA from A. flavus}

The AreA protein was identified in A. flavus from the FungiDB website, with the sequence ID: AFLA_049870. The amino acid sequences of AreA from A. flavus and 12 other fungal species including Aspergillus oryzae, Aspergillus nidulans, Aspergillus niger, Aspergillus parasiticus, Aspergillus clavatus, Aspergillus terreus, Aspergillus nomius, Aspergillus fumigatus, Neosartorya fischeri, Talaromyces marneffei, Acremonium chrysogenum and Penicillium digitatum were obtained from UniProt. The open reading frame (ORF) of the A. flavus areA gene consists of $2668 \mathrm{bp}$, coding for AreA, a transcription factor made up of 866 aa, with a weight of approximately $92.8 \mathrm{KDa}$. The sequence alignment of the aforementioned 
organisms revealed that the GATA zinc finger domain and C-terminal of the AreA protein were highly conserved in the aforementioned organisms (Figure 1A). The phylogenetic tree analysis displayed a close evolution between the AreA protein from A. flavus, A. oryzae, A. parasiticus, and A. nomius, while the relationship was quite far from the AreA protein of $A$. nidulans (Figure 1B). The protein sequence contains two domains, the Nitrogen Regulatory AreA N-terminal (1-88 aa), and the GATA zinc finger (658-711 aa) (Figure 1C).

A.

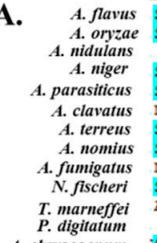

C.
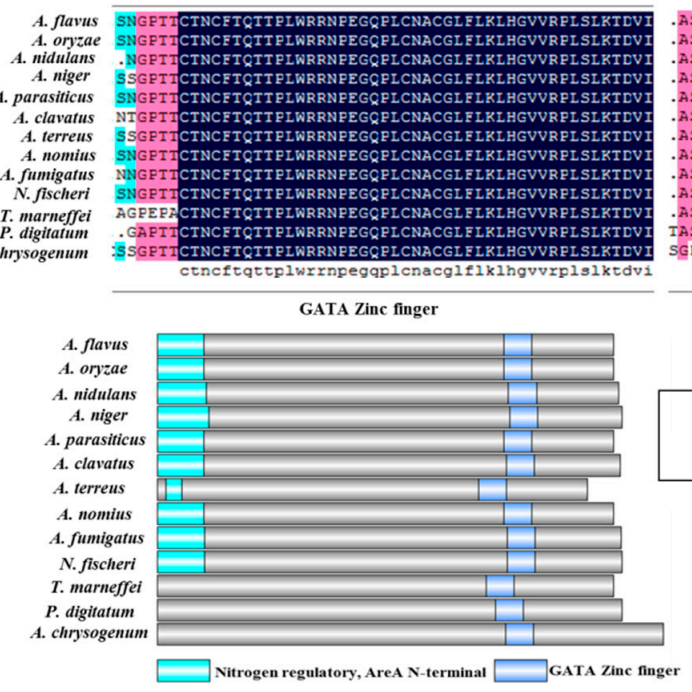

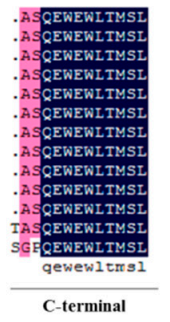

B.
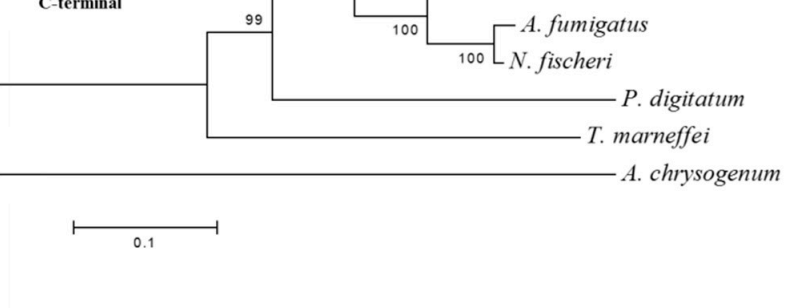

Figure 1. Bioinformatics analysis of major nitrogen regulator AreA. (A) Sequence alignment of the AreA protein amino acid sequence from Aspergillus flavus, Aspergillus oryzae, Aspergillus nidulans, Aspergillus niger, Aspergillus parasiticus, Aspergillus clavatus, Aspergillus terreus, Aspergillus nomius, Aspergillus fumigatus, Neosartorya fischeri, Talaromyces marneffei, Penicillium digitatum and Acremonium chrysogenum, showing the conserved domains. (B) Phylogenetic tree of the AreA protein from organisms described in panel A. (C) Domain prediction of the AreA protein in the aforementioned organisms visualized by DOG 2.0 software.

\subsection{Construction of areA Deletion ( $\triangle$ areA) and Over-Expression (OE::areA) Mutant Strains}

In order to elucidate the role of are $A$ in the morphology, secondary metabolite production and pathogenicity of $A$. flavus, the are A gene was deleted and over-expressed in A. flavus using the homologous recombination method. The obtained transformants were subjected to diagnostic PCR, RT-PCR and qRT-PCR to verify successful gene manipulations. The diagnostic PCR showed the presence of the ORF in the wild-type strain (WT), and the absence of AP (containing part of the $5^{\prime}$ UTR and $p y r G$ ) and BP (containing part of the $3^{\prime}$ UTR and $p y r G$ ) fragments, while the $\triangle$ are $A$ mutant, from which the ORF could not be amplified, displayed the AP and BP amplicons as expected. The diagnostic PCR confirmed the successful deletion of the areA gene (Figure 2A). RT-PCR and qRT-PCR analyses showed an undetectable are $A$ transcript in $\triangle$ are $A$, and a higher are $A$ transcript level in OE::are $A$ when compared with the WT strain (Figure 2B,C). These results further confirmed the successful construction of the $\triangle$ are $A$ and $\mathrm{OE}:$ are $A$ strains. 


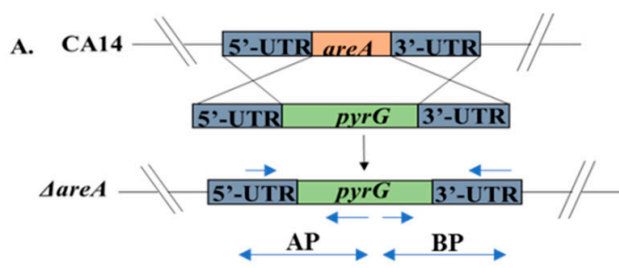

B.

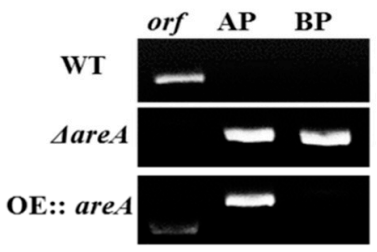

C.

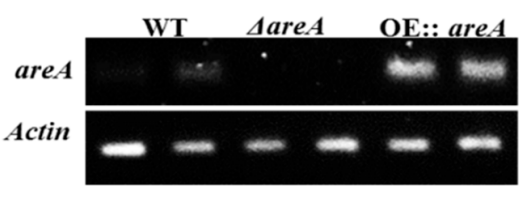

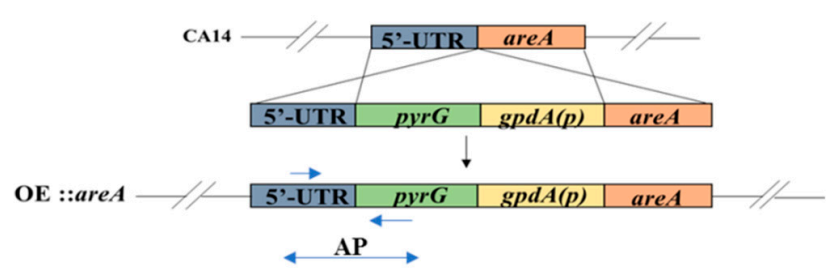

WT OE: : areA

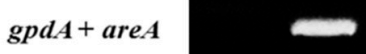

D.

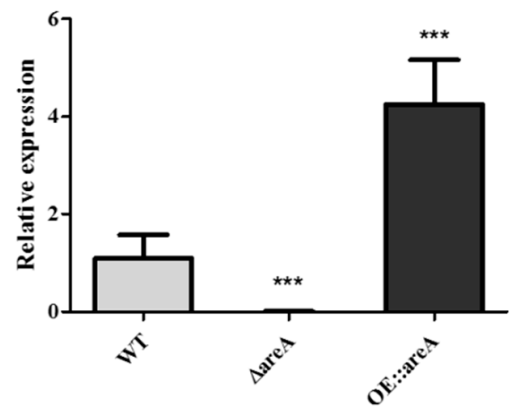

Figure 2. Construction and verification of $\triangle a r e A$ and OE::are $A$ strains. (A) Schematic diagram of the gene manipulation strategy for the construction of $\triangle$ are $A$ and OE::are $A$ strains. (B) Diagnostic PCR for the verification of $\triangle$ are $A$ and OE::areA strains. (C) RT-PCR verification of WT, $\triangle$ are $A$ and OE::areA strains. (D) qRT-PCR verification of WT, $\triangle$ are A and OE::are $A$ strains. Strains were grown on yeast extract-sucrose (YES) medium for $48 \mathrm{~h}$ at $37^{\circ} \mathrm{C}$. *** $p<0.001$. Error bars represent the SE (standard error) from three independent experiments with three replicates.

\section{3. areA is Important for Nitrogen Utilization and Growth of A. flavus}

The growth of $A$. flavus on solid media was affected by the deletion of are $A$, and aerial hyphae development was inhibited in $\triangle$ are $A$ on glucose minimal medium (GMM) supplemented with nitrogen sources, with a high severity in Ala and Pro (Figure 3A). The growth assay revealed a slower growth rate of $\triangle a r e A$ on glucose minimal media supplemented with Ala and Pro (Figure 3B). The lowest growth rate was observed in GMM + Ala, as the $\triangle$ are $A$ mutant could barely grow. It was observed that the growth defect of the $\triangle$ are $A$ mutant could be completely restored on the media supplemented with Gln. Intriguingly, the over-expression strain of areA (OE::areA) grew poorly on the media supplemented with Ala and Pro compared to the wild type (Figure 3A), which indicated that Ala and Pro may induce the expression of areA more largely in the WT strain than in the OE::areA strain. Further observation under a microscope revealed that $\triangle a r e A$ produced mycelia with a lower density, and fewer branches, in comparison with WT and OE::areA strains (Figure 3C). The septa morphology of A. flavus strains were also observed, and we discovered that $\triangle a r e A$ had significantly fewer septa than the WT and OE::areA strains (Figure 3D). These results showed that are $A$ is important for the utilization of non-preferred nitrogen sources and growth in A. flavus. 

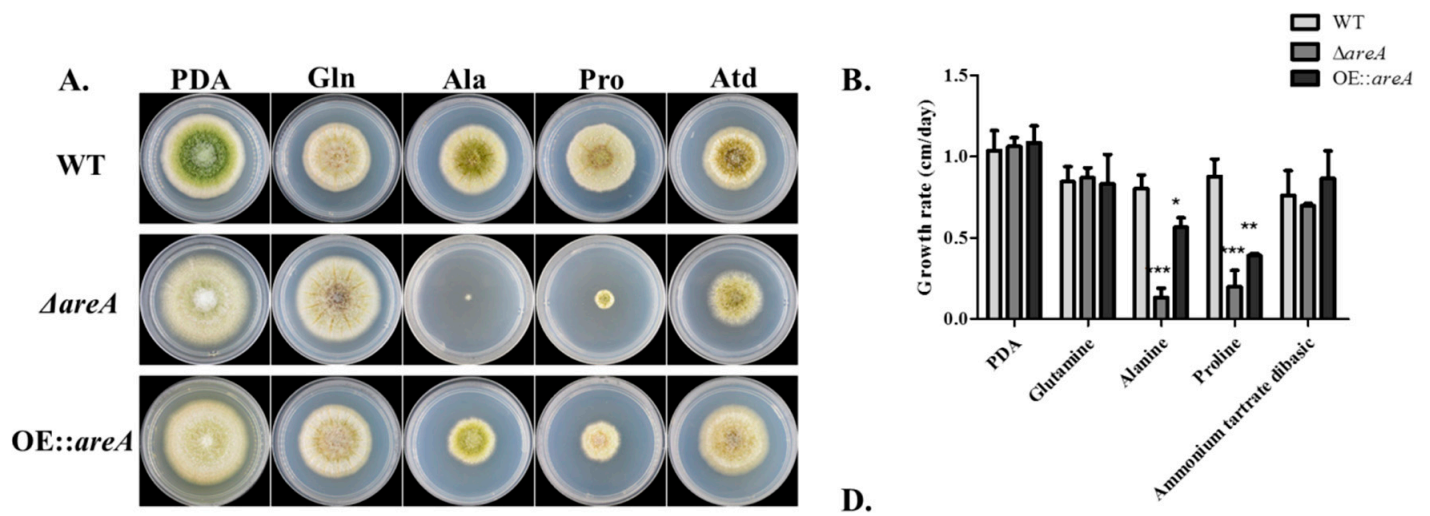

C.
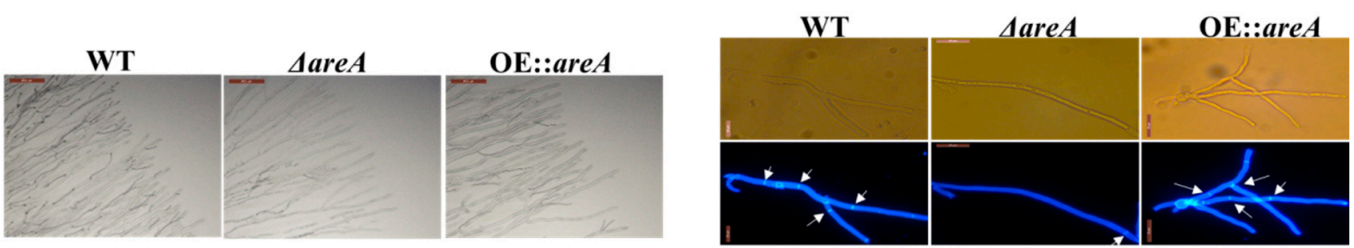

Figure 3. Phenotype, growth rate and mycelial branching of A. flavus strains. (A) Colony morphology of WT, $\triangle$ are A and OE::areA grown on potato dextrose agar (PDA) and glucose minimal medium (GMM) supplemented with $50 \mathrm{mM}$ Glutamine, alanine, proline, or ammonium tartrate dibasic at $37^{\circ} \mathrm{C}$ for 4 d. (B) Growth rate analysis of WT, $\triangle$ are A and OE::areA as panel A. (C) Mycelial branching of WT, $\triangle$ are $A$ and OE::are $A$ on PDA at $37^{\circ} \mathrm{C}$ after $2 \mathrm{~d}$. Bars $=100 \mu \mathrm{m}$. (D) Septa morphology of WT, $\triangle$ are $A$ and OE::are $A$ grown in PDB at $37^{\circ} \mathrm{C}$ overnight. Bars $=20 \mu \mathrm{m}^{*} p<0.05,{ }^{* *} p<0.01$, and ${ }^{* *} p<0.001$. Error bars represent the $\mathrm{SE}$ from three independent experiments with three replicates.

\section{4. areA Influences Conidia Production of A. flavus}

The conidiophore morphology of the A. flavus strains was observed using a microscope, and we observed that the $\triangle$ are $A$ mutant was severely impaired in the formation of conidiophores and failed to form visible conidia due to the undeveloped phialides (Figure 4A). Further, the amount of conidia produced by $\triangle a r e A$ on yeast extract-sucrose (YES) medium was significantly lower than those of the WT and OE::are $A$ strains (Figure 4B). To further understand the results obtained, the transcript levels of the conidia-related genes, $a b a A$ and $b r l A$, were assessed, and we discovered that the transcript level of $b r l A$ was significantly reduced in $\triangle a r e A$ compared to WT and OE::are $A$ strains (Figure $4 \mathrm{C}$ ). These results indicated that are $A$ is required for the full conidiation of $A$. flavus.

A.

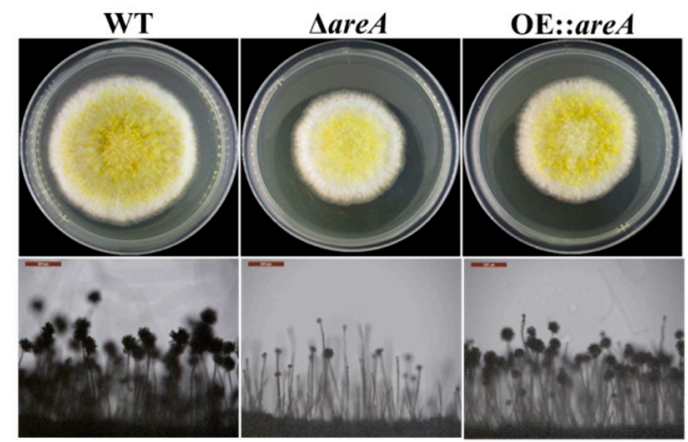

B.

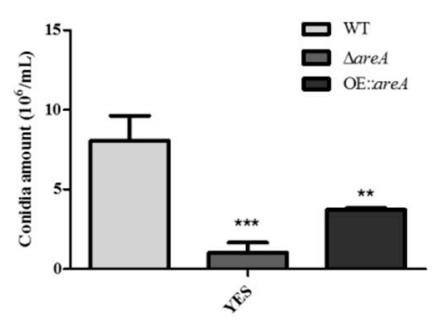

C.

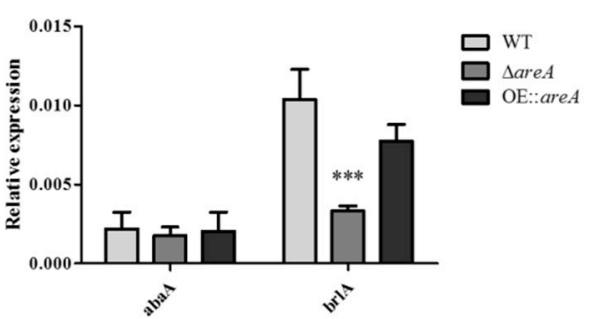

Figure 4. Conidia production of A. flavus strains. (A) Conidiophore morphology of the WT, $\triangle$ are A and 
OE::are A strains of $A$. flavus grown on YES medium at $37^{\circ} \mathrm{C}$ for $4 \mathrm{~d}$. Bars $=200 \mu \mathrm{m}$. (B) Amounts of conidia produced by WT, $\triangle$ are $A$ and OE::are $A$ strains grown on YES medium at $37^{\circ} \mathrm{C}$ for $4 \mathrm{~d}$. (C) The relative expression levels of the conidiation-related genes $a b a A$ and $b r l A$ in the WT, $\triangle$ are $A$ and OE::are $A$ strains of $A$. flavus. ${ }^{* *} p<0.01$ and ${ }^{* * *} p<0.001$. Error bars represent the SE from three independent experiments with three replicates.

\section{5. areA Impedes Sclerotia Formation in A. flavus}

The amount of sclerotia produced by the A. flavus strains was assessed by growing the strains on GMM supplemented with $2 \%$ sorbitol, with Gln as the sole nitrogen source. It was discovered that more sclerotia were produced by $\triangle$ are $A$ in comparison with the WT and OE::areA strains (Figure 5A,B). To shed more light on the result obtained, the transcript levels of sclerotia-related genes, $n s d C, n s d D$ and $s c l R$, were examined, and we found that the transcript levels of $n s d C$ and $n s d D$ genes were similar in all the three test strains, while $s c l R$ was significantly increased in $\triangle a r e A$ compared to the WT and OE::are $A$ strains (Figure 5 C). These results suggested that are $A$, being a nutrition gene, was important for the assimilation of nutrients by $A$. flavus.
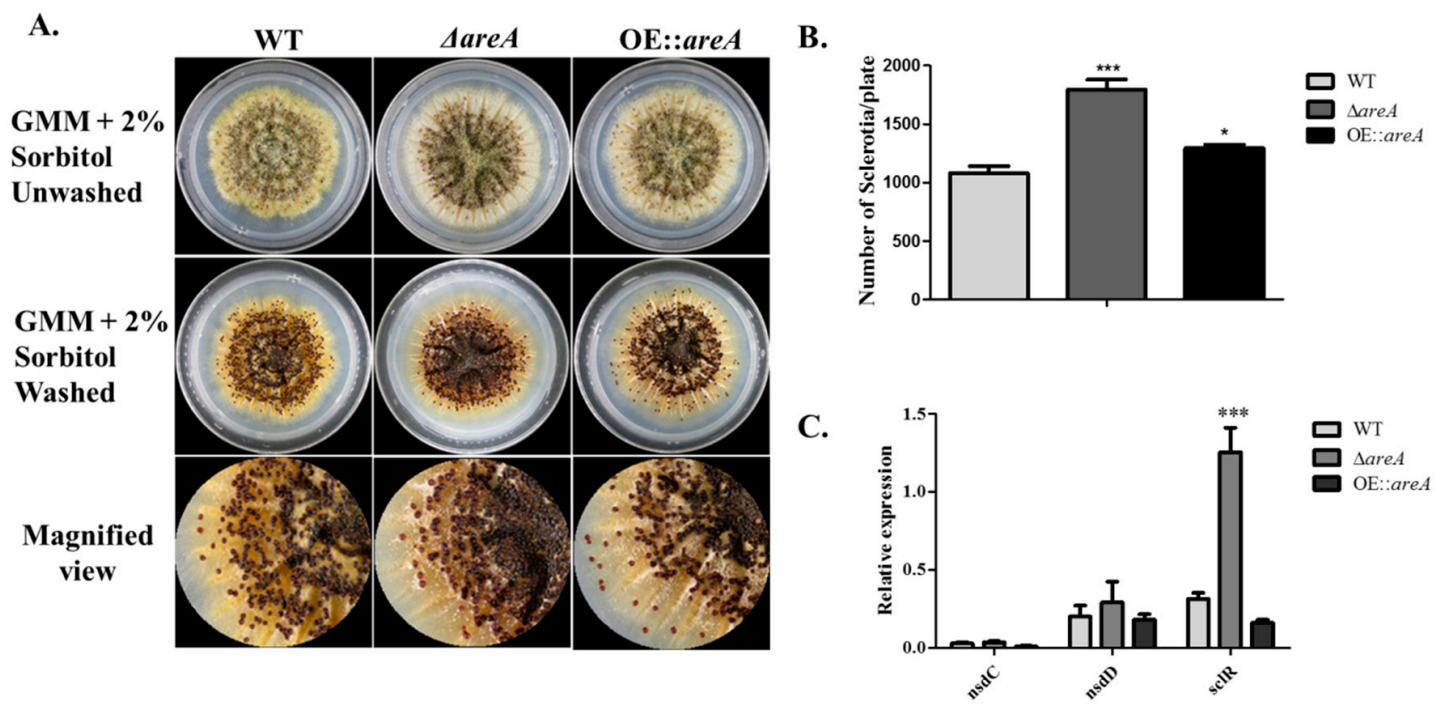

Figure 5. Sclerotia production of $A$. flavus strains. (A) Sclerotia production (before and after washing off the conidia) of the WT, $\triangle$ are $A$ and OE::are $A$ strains on glucose minimal medium (GMM) at $37^{\circ} \mathrm{C}$. (B) Statistical analysis of the sclerotia production. (C) The expression levels of $n s d C, n s d D$ and $s c l R$ genes involved in sclerotia production by qRT-PCR assay. ${ }^{*} p<0.05$ and ${ }^{* * *} p<0.001$. Error bars represent the SE from three independent experiments with three replicates.

\section{6. areA Influences the Stress Responses of A. flavus}

The effect of are $A$ deletion on the response of $A$. flavus to osmotic stress was examined by culturing the strains on potato dextrose agar (PDA), supplemented with $\mathrm{NaCl}$ and $\mathrm{KCl}$ (Figure 6A), and we observed that osmotic stress enhanced the growth of $A$. flavus (Figure 6B). In the oxidative stress assay, both the $\triangle$ are $A$ and OE::areA strains displayed significant growth inhibition in the presence of $\mathrm{H}_{2} \mathrm{O}_{2}$ compared to the wild type (Figure 6). Cell wall stress was induced by two stress agents, Congo Red $(\mathrm{CR})$ and calcofluor white (CFW) (Figure 6A), and the result showed that the relative growth rate of the $\triangle$ are $A$ and $\mathrm{OE}:: a r e A$ strains were significantly inhibited in comparison to the wild-type strain (Figure 6B). These results suggested that areA may play a role in the sensitivity of $A$. flavus to osmotic, oxidative and cell wall stresses. 

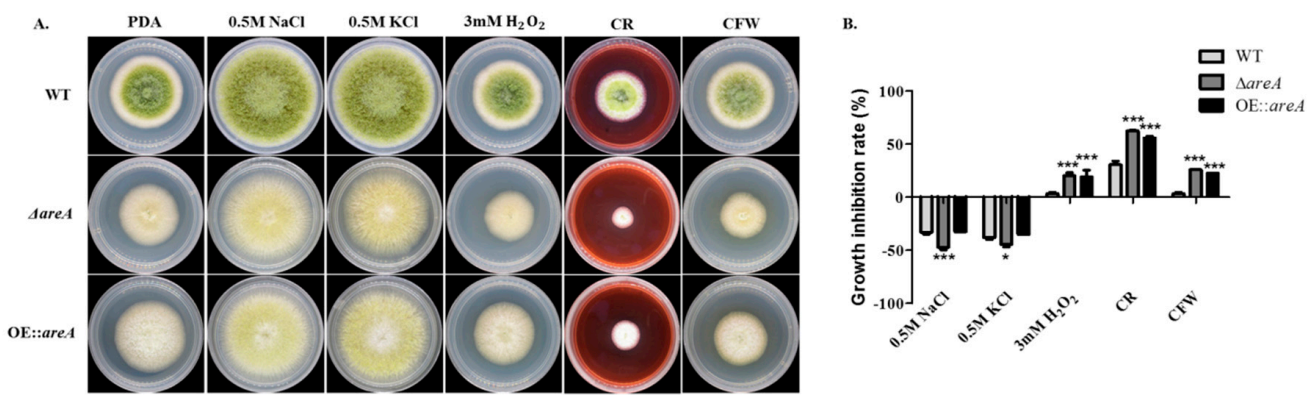

Figure 6. Inhibition of the growth rate of $A$. flavus strains under different stress conditions. (A) Colony morphology of the WT, $\triangle$ are $A$ and OE::areA strains grown on PDA, or PDA containing $0.5 \mathrm{~mol} / \mathrm{L} \mathrm{NaCl}$ and $\mathrm{KCl}, 3 \mathrm{mM} \mathrm{H}_{2} \mathrm{O}_{2}, 300 \mu \mathrm{g} / \mathrm{mL}$ Congo Red (CR), and $100 \mu \mathrm{g} / \mathrm{mL}$ calcofluor white $(\mathrm{CFW})$ at $37^{\circ} \mathrm{C}$ for $4 \mathrm{~d}$, respectively. (B) The inhibition of the growth rate of the strains in panel A. ${ }^{*} p<0.05$ and ${ }^{* * *} p<0.001$.

\subsection{Aflatoxin Biosynthesis is Partially Regulated by AreA}

Aflatoxin B1 (AFB1) is the most important and toxic secondary metabolite produced by A. flavus. Here, we found by thin layer chromatography (TLC) assay, that the lack of areA promoted AFB1 biosynthesis in PDB medium compared to the wild-type and over-expression (OE::areA) strain (Figure 7A). However, there was no significant difference observed in the AFB1 production of the three strains in YES medium. Intriguingly, when glutamine or ammonium tartrate dibasic was used as the sole nitrogen source, AFB1 production was inhibited in $\triangle$ are $A$, but accumulated in OE::are $A$ (Figure 7A,B). As expected, the $\triangle a r e A$ and OE::are $A$ strains produced decreased amounts of AFB1 in the presence of proline and alanine, since these two strains grew poorly when proline and alanine were used as the sole nitrogen source. Although the activity of AreA might be inhibited in the wild-type strain in the presence of glutamine or ammonium, the wild-type strain produced detectable AFB1 (Figure 7A,B). We investigated the expression levels of some genes in the aflatoxin biosynthesis gene cluster (BGC), and we discovered that the expression levels of the cluster activator, aflR, and enhancer, aflS were not significantly reduced in the $\triangle$ areA strain when compared with the WT strain, while the expression levels of the other genes examined (aflK, aflO, aflP and aflQ) were significantly increased (Figure 7C). These results suggested that AFB1 biosynthesis in A. flavus was partially regulated by are $A$ and may be influenced via a different pathway independent of AreA from nitrogen metabolism.
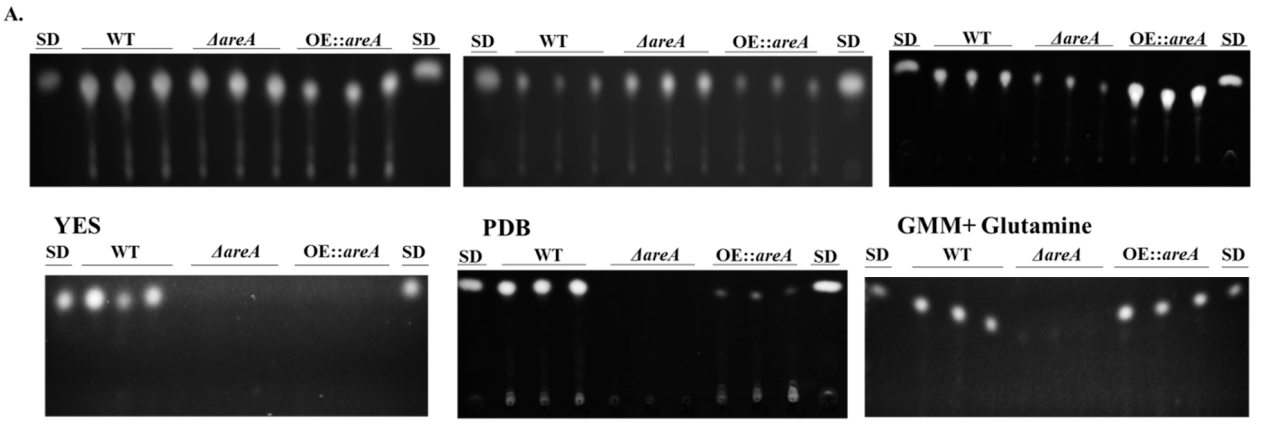

GMM+ Glutamine
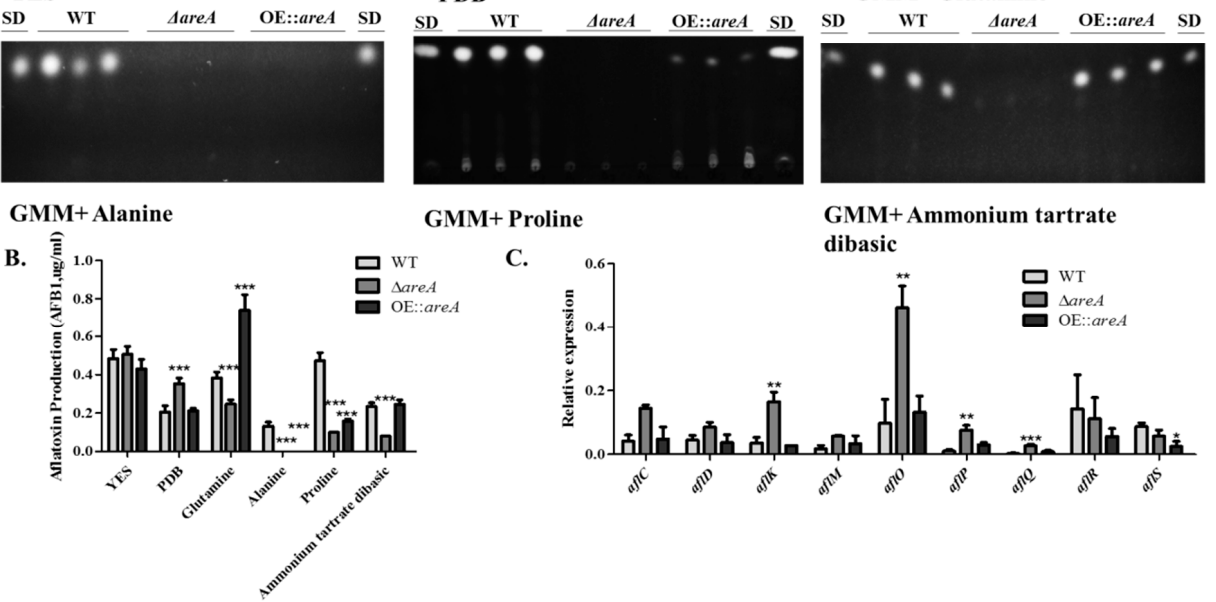

GMM+Ammonium tartrate dibasic

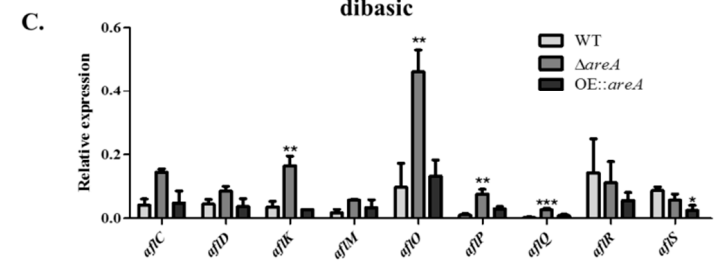

Figure 7. Aflatoxin B1 (AFB1) biosynthesis of A. flavus strains. (A) Thin layer chromatography (TLC) 
assay of AFB1 produced by WT, $\triangle$ are A and OE::areA strains grown on YES medium, PDB and GMM supplemented with $50 \mathrm{mM}$ Gln, Pro, Ala or $\mathrm{NH}_{4}$ at $29{ }^{\circ} \mathrm{C}$ for $6 \mathrm{~d}$. (SD indicates standard AFB1.) (B) Quantification assay of AFB1 produced in panel A. (C) The expression levels of aflC, aflD, aflK, aflM, aflO, aflP, aflQ, aflR, and aflS genes involved in aflatoxin biosynthesis by qRT-PCR assay. Error bars represent the SE from three independent experiments with three replicates. ${ }^{*} p<0.05,{ }^{* *} p<0.01$ and $* * * p<0.001$.

\section{8. areA is Necessary for the Pathogenicity of A. flavus}

A. flavus is known to readily colonize oil-rich crop seeds. Hence, we investigated the effect of are $A$ deletion on the colonization of peanut seeds. The assay revealed that the loss of areA caused a significant impairment in the pathogenicity of the strain on peanut seeds (Figure 8A). The pathogenicity of the strains was assessed based on the mycelia and conidia produced on the surface of the infected seeds. The result showed that the $\triangle a r e A$ mutant grew less vigorously on peanut seeds (Figure $8 \mathrm{~A}$ ). Further, the conidia quantification assay revealed that $\triangle a r e A$ was significantly impaired in conidiation compared to the WT and OE::areA strains (Figure 8B). Further quantification of AFB1 production from the infected plant seeds showed a significant decrease in $\triangle a r e A$ in comparison with the WT strain (Figure $8 C, D$ ). These results suggested that are $A$ is necessary for the pathogenicity of $A$. flavus.

A.

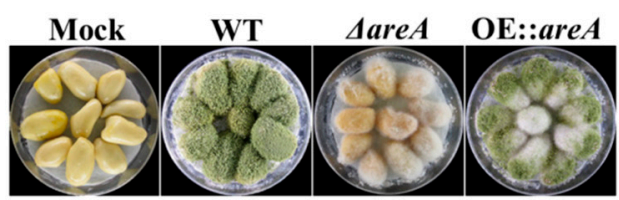

C.

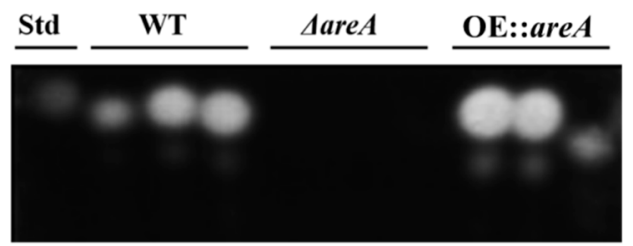

B.

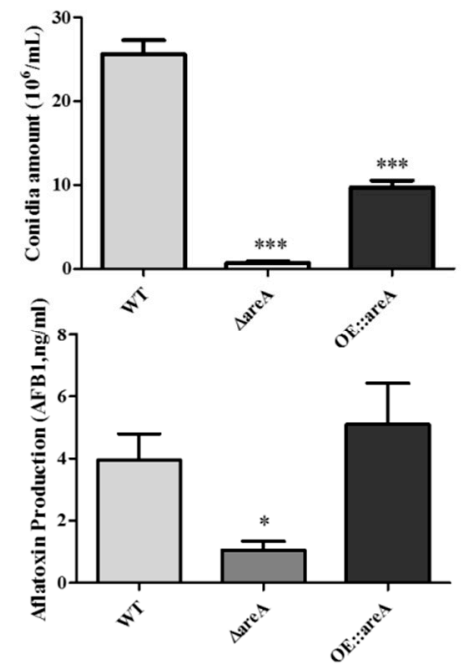

Figure 8. Pathogenicity assay of A. flavus. (A) Morphology of A. flavus WT, $\triangle$ are A and OE::areA strains on peanut seeds after $6 \mathrm{~d}$ of inoculation. (B) Conidia production of strains in panel A. (C) TLC analysis of AFB1 extracted from panel A. (SD indicates standard AFB1.) (D) Quantification of TLC result in panel C. ${ }^{*} p<0.05$ and ${ }^{* * *} p<0.001$. Error bars represent the SE from three independent experiments with three replicates.

\subsection{Subcellular Localization of AreA in A. flavus}

The subcellular localization of AreA was investigated by culturing A. flavus strains expressing areA tagged with RFP (red fluorescence protein) in GMM supplemented with different nitrogen sources. The samples were stained with 4,6-diamidino-2-phenylindole (DAPI) to enable a clear view of the nucleus. AreA was seen to be localized both in the nucleus and in the cytoplasm, under a nitrogen-limited condition (presence of alanine and proline), mainly in the cytoplasm in the presence of ammonium, while the signal could barely be seen under a nitrogen-repressed condition (presence of glutamine) (Figure 9). This result confirms the transcription activity of AreA and its involvement in nitrogen metabolism. 


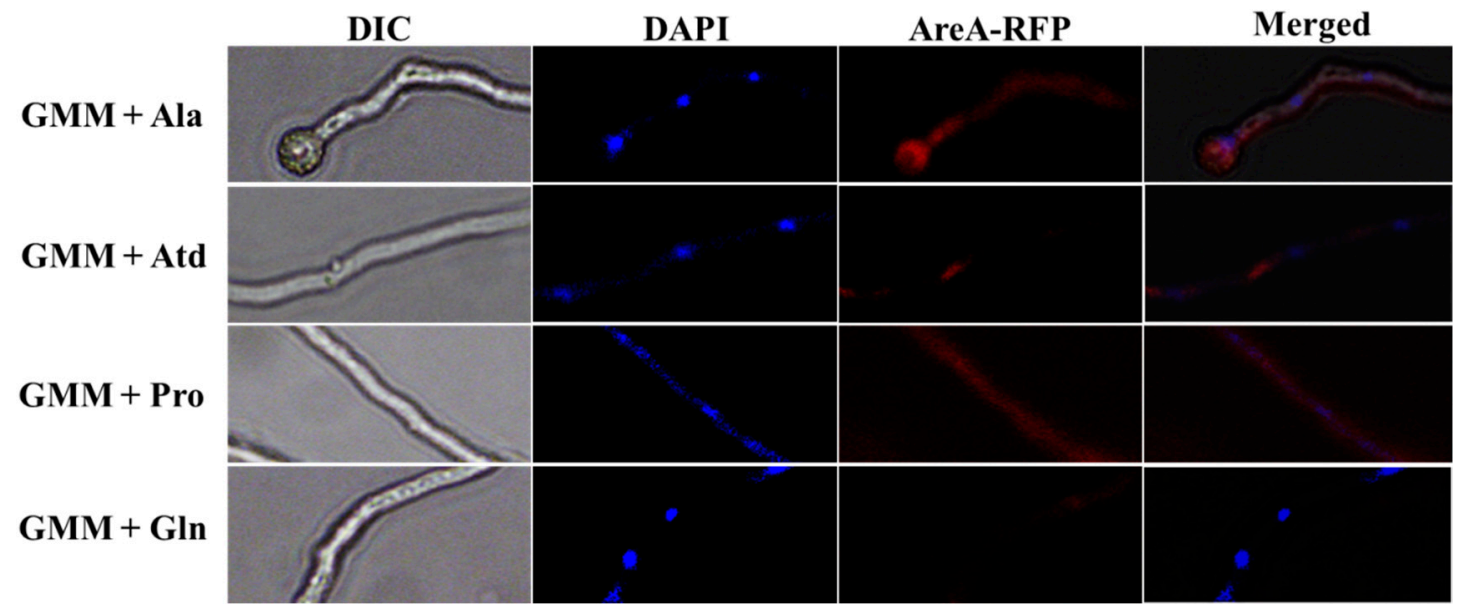

Figure 9. Subcellular localization of AreA in A. flavus. Confocal scanning images of AreA::RFP in vegetative mycelium. The AreA::RFP strain was cultured for $16 \mathrm{~h}$ at $37^{\circ} \mathrm{C}$ in GMM supplemented with $50 \mathrm{mM}$ Gln, Pro, Ala or $\mathrm{NH}_{4}$. Bars $=10 \mu \mathrm{m}$.

\section{Discussion}

The ability of $A$. flavus to utilize a wide range of nutrients with different qualities and quantities is essential for its pathogenicity, as it has previously been shown that the expression of virulence-related genes is induced by nitrogen starvation $[18,20]$. Fungi are able to utilize several nitrogen sources, subject to the regulatory mechanism NMR, which allows the use of a preferred nitrogen source like glutamine and ammonium over secondary nitrogen sources [32,35]. In this study, we characterized the function of the major nitrogen regulatory gene are $A$ in A. flavus. Its deletion resulted in a defective utilization of secondary nitrogen sources, and a slightly ineffective use of ammonium, which is a preferred source of nitrogen in A. nidulans [36]. In consonance with our findings, the ineffective use of ammonium has been recorded in the deletion of an areA ortholog in A. oryzae [37] and F. graminearum [35]. Here, we found that the absence of are $A$ was only compensated for, by the presence of glutamine, in the utilization of nutrients for proper growth, suggesting that glutamine is a preferred source of nitrogen for $A$. flavus. This is in contrast with the study of areA in A. nidulans, where glutamine is a non-preferred source [36]. A study performed by Min and colleagues also showed that neither glutamine nor ammonium is a preferred nitrogen source in Fusarium zeae, but rather urea [38].

$\operatorname{are} A$, being the major regulator of nitrogen metabolism, is expected to affect the vegetative development of $A$. flavus, as nitrogen is among the most essential nutrients for the growth and differentiation of organisms [39]. Hence, we investigated this by examining the colony diameter of A. flavus strains on different culture media, and also by viewing the mycelial branching and septa morphology of $A$. flavus strains grown in complete medium. The degree of branching of fungal mycelial is essential for the assimilation of nutrients by the fungus, and the presence of septa indicates the growth and maturation of new cells. We discovered that are $A$ deletion led the formation of less dense mycelial branches and few septa, indicating that are $A$ positively regulates the growth and development of A. flavus.

The regulation of conidiation in filamentous fungi involves certain regulators such as $V e A / V e 1, V e l B$, Wet $A, b r l A$ and $a b a A$ [40]. In the fruit postharvest pathogen Colletotrichum gloeosporioides, the deletion of $C$ gare $A$ up-regulated $V e 1$, resulting in an increased conidia production [34]. Here, we found that are $A$ influenced the conidiation of $A$. flavus, as its deletion resulted in a significantly decreased the amount of conidia when grown on both complete and minimal media containing different nitrogen sources. Further, we found that the conidiophore produced by the $\triangle$ are $A$ mutant was poorly formed, which is consistent with the down-regulated the expression level of $b r l A$ observed in the are $A$ deletion strain. These data suggested that the absence of $\operatorname{are} A$, not the quality of nitrogen source, was the cause of the reduction of conidia production in A. flavus. 
The production of secondary metabolites in fungi is influenced by the available nitrogen sources and nitrogen regulators [39,41,42]. GATA transcription factors are known to influence the utilization of nutrients, morphology or growth of Aspergillus, and their disruption may also cause a significant down-regulation of the AF biosynthesis genes expression, but not a total lack [43]. AreA is a positive regulator of the expression of genes related to the production of several secondary metabolites like GA, fumonisin, DON, zearalenone, fusarielin $\mathrm{H}$, beauvericin and cephalosporin [43]. AreA, as a GATA transcription factor, has binding sites in the promoters of key genes in the AF biosynthesis cluster [44], suggesting that AreA may have a direct influence on the expression of these genes. The aflJ-aflR (aflJ, now called aflS) intergenic region also has approximately five AreA binding sites [43]. Additionally, certain aflatoxigenic strains of $A$. flavus, $A$. sojae, and A. oryzae reported to have full transcription of aflR, but had no expression of $a f l O$, produced no aflatoxin. This implies that although aflR may induce the transcription of AF biosynthesis pathway genes, other factors may affect the expression levels of the genes [45]. We investigated the expression levels of some genes in the AF BGC in A. flavus when cultured on YES medium, including the cluster activator, aflR, the cluster expression enhancer, aflS, and some other genes responsible for the production of the AF pathway intermediates $(a f l C$, aflD, aflK, aflM, aflO, aflP, and aflQ). We discovered that the expression levels of aflR and aflS were not significantly down-regulated in $\triangle a r e A$ in comparison with the WT strain, however, the expression levels of aflK, aflO, aflP and aflQ were significantly up-regulated in the $\triangle a r e A$ strain. Our results in conjunction with previous findings suggested that in A. flavus, although aflR is responsible for the activation of the transcription of the AF BGC, additional factors may affect the expression levels of the pathway genes. It has been previously reported that, the nitrogen sources available to $A$. flavus affected its biosynthesis of AFB1, and glutamine was reported by a previous study in our lab as the optimal nitrogen source for the production of AFB1 [12]. However, in this study, we discovered that the WT strain produced more AFB1 in GMM supplemented with proline as the nitrogen source than in the presence of glutamine, while the highest amount of AFB1 was produced by OE::areA when grown in GMM supplemented with glutamine. The gene deletion mutant grows better than the WT strain on glutamine. This suggests that as much as glutamine inhibits the function of $\operatorname{are} A$, the presence of are $A$ does not give room for the complete utilization of glutamine as a nitrogen source. However, in the case of proline, the gene deletion mutant grew poorly, which indicated that the utilization of proline needs areA. This implied that the WT strain may be able to utilize proline better than glutamine, and this was evident in the slightly increased colony size and AFB1 quantity in the proline-containing medium. On the other hand, despite the ability of proline to be utilized as both nitrogen and carbon source, it could not rescue the lack of the function of areA in AFB1 production, and this may be due to carbon catabolite repression induced by glucose [46]. It has been previously shown in A. nidulans that AreA is not sufficient for the utilization of proline, and the presence of CreA hinders the action of the element required for its full utilization [47]. The loss of are $A$ and the presence of $c r e A$ therefore poses a double-fold hindrance to the utilization of proline, and this could be the cause of the inability of the areA deletion mutant of A. flavus to utilize proline both for growth and AFB1 production.

The system responsible for the regulation of osmotic stress in fungi has previously been shown to be connected to fungal development, and previous studies show that in A. flavus, osmotic stress induced by high concentrations of $\mathrm{NaCl}$, sorbitol, and $\mathrm{KCl}$ has positive effects on vegetative growth, leading to increased conidiation [48]. In this study, we observed that osmotic stress induced by $\mathrm{NaCl}$ and $\mathrm{KCl}$ not only improved the growth of the wild-type strain of A. flavus, but that of the $\triangle$ areA mutant was also significantly increased. This may be as a result of the optimal utilization of the materials and energy dispensed by the fungus for development in a bid to provide favorable survival conditions, in response to osmotic stress [48], by the $\triangle$ are A mutant. Due to the ability of the $\triangle$ are $A$ mutant to conveniently utilize whichever nutrient source available to it, as it does not have to strive for the utilization of non-preferred nitrogen sources, according to the function of the are $A$ gene.

During the colonization of hosts by pathogenic fungi, the ability to surmount diverse detrimental environmental conditions, especially an oxidative surge which may lead to an accumulation of 
extremely harmful reactive oxygen species (ROS), is a requirement for fungal pathogens. Plants have been shown to produce harmful ROS, as a form of defense to counter pathogens [49,50]. Because of the relative stability of $\mathrm{H}_{2} \mathrm{O}_{2}$ and its ability to easily diffuse through membranes, it acts as a means of communication for cells to initiate defense response [51]. $\mathrm{H}_{2} \mathrm{O}_{2}$ is also synthesized in large amounts in a mechanism known as a hypersensitive reaction (HR), employed by plant cells to counter the invasion of pathogens [52,53]. Here, we observed that the growth of the $\triangle a r e A$ mutant was significantly inhibited by oxidative stress, which implied that the gene are $A$ may play a role in reducing the susceptibility of A. flavus to oxidative stress, which further implies that areA may help shield A. flavus from the counter attacks of the host plant during infection.

Snoeijers and colleagues showed that the accessibility of nitrogen is important for colonization and pathogenicity [54]. The virulence of $A$. flavus has been said to be dependent on several factors, one of which is not aflatoxin [6] - unlike in F. zeae wheat head blight, where trichothecenes are virulence factors [55]. It has been reported that a shortage in the nitrogen supply of plant pathogens at the start of the infection process gives a signal for the commencement of infection $[25,56]$. In this study, the ability of $A$. flavus to effectively colonize hosts was impaired by the deletion of $\operatorname{are} A$, and the conidiation and AFB1 production of the $\triangle a r e A$ mutant were found significantly reduced on hosts. These results were in consonance with the AreA studies in F. verticillioides [31], Ustilago maydis [56], and C. gloeosporioides [34], but different from that of Magnaporthe grisea [16].

Transcription factors are localized to the nucleus under conditions in which they carry out their transcription activity [57]. Hence, it is expected that AreA would be localized in the nucleus under nitrogen starvation conditions, as it effects the expression of genes related to the exploitation of less preferred nitrogen sources. We discovered that AreA was localized in the nucleus and also in the cytoplasm under nitrogen starvation conditions, while it was mainly localized in the cytoplasm in the presence of ammonium.

In conclusion, AreA, as a global transcription factor, is involved in many pathways and mechanisms in A. flavus other than nitrogen metabolism. Further, the gene is important for both the primary and secondary metabolism of $A$. flavus, irrespective of the nitrogen source present. However, further studies need to be carried out to elucidate the mechanism through which areA plays its roles in A. flavus.

\section{Materials and Methods}

\subsection{Strains and Culture Conditions}

The fungal strains and plasmids used in this study are listed in Table 1. In this study, the culture media used include, glucose minimal medium (GMM, $10 \mathrm{~g} / \mathrm{L}$ glucose, $6 \mathrm{~g} / \mathrm{L} \mathrm{NaNO}$, $1.52 \mathrm{~g} / \mathrm{L} \mathrm{KH}_{2} \mathrm{PO}_{4}$, $0.52 \mathrm{~g} / \mathrm{L} \mathrm{KCl}, 0.52 \mathrm{~g} / \mathrm{L} \mathrm{Mg} 2 \mathrm{SO}_{4} \cdot 7 \mathrm{H}_{2} \mathrm{O}$, and $1 \mathrm{~mL}$ trace elements), yeast extract-sucrose (YES, $20 \mathrm{~g} / \mathrm{L}$ yeast extract, $150 \mathrm{~g} / \mathrm{L}$ sucrose, $1 \mathrm{~g} / \mathrm{L} \mathrm{Mg}_{2} \mathrm{SO}_{4} \cdot 7 \mathrm{H}_{2} \mathrm{O}$ ), yeast extract-glucose agar (YGT, $5 \mathrm{~g} / \mathrm{L}$ yeast extract, $20 \mathrm{~g} / \mathrm{L}$ glucose, $1 \mathrm{~mL}$ trace elements) with or without uracil and uridine, potato dextrose agar (PDA, BD Difco $^{\mathrm{TM}}$, Franklin, NJ, USA), potato dextrose broth (PDB, BD Difco ${ }^{\mathrm{TM}}$, Franklin, NJ, USA) and Czapek agar (CA, BD Difco ${ }^{\mathrm{TM}}$, Franklin, NJ, USA, $1 \mathrm{M}$ sucrose, $10 \mathrm{mM}$ ammonium tartrate dibasic). $15 \mathrm{~g} / \mathrm{L}$ agar was added for solid media. All strains were cultured at $37^{\circ} \mathrm{C}$ for growth, and $29^{\circ} \mathrm{C}$ for aflatoxin analysis $[23,58,59]$. All experiments were carried out in triplicate, with each strain having four plates.

Table 1. Strains used in this study.

\begin{tabular}{ccc}
\hline Strain & Characterization & Source \\
\hline A. flavus SRRC1709 (CA14PTS) & $\Delta k u 70, \Delta p y r G$, and $\Delta n i a D$, Used for gene deletion & {$[60]$} \\
WT & $\Delta k u 70, \Delta p y r G:$ AfpyrG, $\Delta n i a D$ & This study \\
$\Delta$ areA & $\Delta k u 70, \Delta p y r G::$ AfpyrG, $\Delta n i a D, \Delta a r e A$ & This study \\
OE::areA & $\Delta k u 70, \Delta p y r G, \Delta n i a D, \operatorname{gpd} A(p):$ areA $:$ AfpyrG & This study \\
\hline
\end{tabular}




\subsection{Bioinformatics Analysis of AreA Sequence}

The AreA protein sequences of A. flavus (AFLA_049870) were obtained from FungiDB, and A. oryzae (O13415), A. nidulans (P17429), A. fumigatus (A0A0J5PGE9), A. parasiticus (Q9Y7E8), A. clavatus (A1CMX8), A. niger (O13412), A. nomius (A0A0L1IRC7), A. terreus (Q0CGC8), Neosartorya fischeri (A1DL08), Penicillium digitatum (K9G1P2), Talaromyces marneffei (A0A093VHJ1), and Acremonium chrysogenum (S5YAT5) were obtained from UniProt (www.uniprot.org). The phylogenetic tree was constructed with the downloaded sequences, using MEGA 5.1 software [61]. Domain prediction of the AreA protein in the aforementioned organisms was visualized by DOG 2.0 software (Lab of Cell Dynamics, and Lab of Nanobiology, University of Science \& Technology of China, Hefei, Anhui, China, 2014).

\subsection{Targeted Deletion and Over-Expression of the A. flavus areA Gene}

We created the are $A$ gene deletion mutant $(\triangle a r e A)$ using the method of homologous recombination, in which the ORF of $A$. flavus are $A$ was replaced by $A$. fumigatus pyrG. We constructed a vector A-pyrG-B, containing $1000 \mathrm{bp}$ of the sequences flanking the are $A$ gene, both upstream and downstream, and $p y r G$. These three fragments were fused by overlap PCR. A and B were amplified from the genomic DNA of $A$. flavus using the primer pairs are A-AF/areA-AR and areA-BF/areA-BR, respectively, and Af $p y r G$ gene was amplified with the primers $p y r G-F / p y r G-R$. The overlap PCR was carried out using a pair of nested primers areA-NF/areA-NR. The resulting construct was then transformed into the protoplasts of $A$. flavus SRRC1709 [62]. The over-expression strain (OE::areA) was constructed by replacing the native promoter of $A$. flavus are $A$ with another promoter from $A$. nidulans, $g p d A(\mathrm{p})$. This was also carried out by homologous recombination, and the vector A-pyrG-gpdA(p)-areA, containing A and pyrG as in the deletion mutant, was constructed. The $g p d A(\mathrm{p})$ fragment was amplified from the gDNA of $A$. nidulans with the primer pair $g p d A(\mathrm{p})-\mathrm{F} / g p d A(\mathrm{p})-\mathrm{R}$, and are $A$ was amplified by the primer pair A-gpdA-F/A-gpdA-R. The fragments were fused together by overlap PCR with the primers A-gpdA-NF and A-gpdA-NR. The resulting construct was then transformed into the A. flavus SRRC1709 strain. Gene-specific primers are shown in Table 2.

Table 2. Primers used in this study.

\begin{tabular}{|c|c|c|}
\hline Primer Name & Sequence $5^{\prime}$ to $3^{\prime}$ & Application \\
\hline $\operatorname{are} A-\mathrm{F}$ & ATTCGTAATACCTGCGTTCC & \multirow{2}{*}{ are $A$ gene cloning } \\
\hline $\operatorname{are} A-\mathrm{R}$ & GGGTGAAGAGCATTGTTTGAGGCCAGTCTACCCGCCCTAAA & \\
\hline $\operatorname{are} A-\mathrm{AF}$ & ATTCGTAATACCTGCGTTCC & \multirow{2}{*}{ 5' UTR fragment amplification } \\
\hline $\operatorname{are} A-\mathrm{AR}$ & GGGTGAAGAGCATTGTTTGAGGCCAGTCTACCCGCCCTAAA & \\
\hline $\operatorname{are} A-\mathrm{BF}$ & GCATCAGTGCCTCCTCTCAGACGAGGTGCAATGCGTTGGT & \multirow{2}{*}{ 3' UTR fragment amplification } \\
\hline $\operatorname{are} A-B R$ & CTGGCCTGAAAGTGGGTG & \\
\hline pyrG-F & GCCTCAAACAATGCTCTTCACCC & \multirow{2}{*}{ pyrG amplification } \\
\hline pyrG-R & GTCTGAGAGGAGGCACTGATGC & \\
\hline $\operatorname{are} A-\mathrm{OF}$ & CCCAGTTGCCCAACCAGGAG & \multirow[b]{2}{*}{ are $A$ ORF verification } \\
\hline $\operatorname{are} A-\mathrm{OR}$ & GGTCGAGTAATTGGTGGCGTTC & \\
\hline $\operatorname{are} A-\mathrm{NF}$ & GTTTGACCGTCGCCTCAGTA & \multirow[b]{2}{*}{ Fusion PCR } \\
\hline $\operatorname{are} A-\mathrm{NR}$ & GGGTGGGTTGTTCGTGTTAG & \\
\hline$A-g p d A-\mathrm{F}$ & СTTTCCCACTTCATCGCAGCTTGATGTCCGGGTTAACCCTCGG & \multirow{2}{*}{$\begin{array}{l}\text { areA ORF amplification for } \\
\text { over-expression }\end{array}$} \\
\hline$A-g p d A-\mathrm{R}$ & GGGCGTCCAAGGCATAATCG & \\
\hline gpdA-F & GATCCCGTAATCAATTGCCCCATCCGGATGTCGAAGGCTT & \multirow{2}{*}{$g p d A(\mathrm{p})$ amplification } \\
\hline$g p d A-\mathrm{R}$ & GTGATGTCTGCTCAAGCGGGG & \\
\hline P801-R & CAGGAGTTCTCGGGTTGTCG & AP fragment verification \\
\hline P1020-F & ATCGGCAATACCGTCCAGAAGC & $\mathrm{BP}$ fragment verification \\
\hline$a b a A-F$ & TCTTCGGTTGATGGATGATTTC & qRT-PCR \\
\hline$a b a A-\mathrm{R}$ & CCGTTGGGAGGCTGGGT & qRT-PCR \\
\hline brlA-F & GCCTCCAGCGTCAACCTTC & qRT-PCR \\
\hline brlA-R & TCTCTTCAAATGCTCTTGCCTC & qRT-PCR \\
\hline sclR-F & CAATGAGCCTATGGGAGTGG & qRT-PCR \\
\hline$s c l R-R$ & ATCTTCGCCCGAGTGGTT & qRT-PCR \\
\hline$n s d C-F$ & GCCAGACTTGCCAATCAC & qRT-PCR \\
\hline$n s d C-\mathrm{R}$ & CATCCACCTTGCCСТTTA & qRT-PCR \\
\hline
\end{tabular}


Table 2. Cont.

\begin{tabular}{|c|c|c|}
\hline Primer Name & Sequence $5^{\prime}$ to $3^{\prime}$ & Application \\
\hline$n s d D-F$ & GGACTTGCGGGTCGTGCTA & qRT-PCR \\
\hline$n s d D-R$ & AGAACGCTGGGTCTGGTGC & qRT-PCR \\
\hline $\operatorname{are} A-\mathrm{F}$ & GAAACGGACGAGGCTAACAA & qRT-PCR \\
\hline $\operatorname{are} A-\mathrm{R}$ & ATACTATGGTTCGCCGGATTG & qRT-PCR \\
\hline aflO-F & GATTGGGATGTGGTCATGCGATT & PT PCP \\
\hline aflO-R & GCCTGGGTCCGAAGAATGC & qRI-ICK \\
\hline aflQ-F & GTCGCATATGCCCCGGTCGG & \\
\hline aflQ-R & GGCAACCAGTCGGGTTCCGG & qRI-PCR \\
\hline aflC-F & GTGGTGGTTGCCAATGCG & RTT-PCR \\
\hline aflC-R & CTGAAACAGTAGGACGGGAGC & \\
\hline aflD-F & GTGGTGGTTGCCAATGCG & \\
\hline aflD-R & CTGAAACAGTAGGACGGGAGC & qRI-PCR \\
\hline aflM-F & ATGTCCGACAACCACCGTTTAGATGGCA & \\
\hline aflM-R & CAATGATCTTTCCACTTACCCATTCGGCTG & qRT-PCR \\
\hline aflK-F & GAGCGACAGGAGTAACCGTAAG & RT PCP \\
\hline aflK-R & CCGATTCCAGACACCATTAGCA & qRI-ICK \\
\hline aflP-F & ACGAAGCCACTGGTAGAGGAGATG & gRT-PCR \\
\hline aflP-R & GTGAATGACGGCAGGCAGGT & qR1-PCK \\
\hline aflR-F & AAAGCACССТGTCTTCССТАAC & aRT-PCR \\
\hline aflR-R & GAAGAGGTGGGTCAGTGTTTGTAG & qRI-PCR \\
\hline actin $-\mathrm{F}$ & ACGGTGTCGTCACAAACTGG & qRT-PCR \\
\hline actin- $\mathrm{R}$ & CGGTTGGACTTAGGGTTGATAG & qRT-PCR \\
\hline
\end{tabular}

\subsection{Growth, Conidia and Sclerotia Production Analysis}

PDA and GMM supplemented with $50 \mathrm{mM}$ nitrogen source (glutamine, Gln; alanine, Ala; proline, Pro; or ammonium tartrate dibasic, $\mathrm{NH}_{4}$ ) agar media were used for analysis of growth rate. A total amount of $10^{6}$ conidia of each strain (WT, $\triangle a r e A$, and OE::are A) were point-inoculated onto plates containing the aforementioned media. Each medium had 4 replicates. The plates were incubated at $37^{\circ} \mathrm{C}$ for $4 \mathrm{~d}$ in the dark, with a daily measurement of the colony diameter of each strain on every plate. Mycelial branching of $A$. flavus strains was observed by point inoculating the strains on a glass slide covered with a thin layer of PDA medium and culturing at $37^{\circ} \mathrm{C}$ for $2 \mathrm{~d}$. Septa morphology was observed from an overnight culture of A. flavus strains at $37^{\circ} \mathrm{C}$, and the culture was stained with CFW to enable a clear view of the diaphragm.

A. flavus strains were cultured on YES medium at $37^{\circ} \mathrm{C}$ for $4 \mathrm{~d}$. Three plugs were taken along a radius of each plate into new tubes after $4 \mathrm{~d}$, then conidia were homogenized and diluted with $5 \mathrm{~mL}$ distilled water and counted using a hemocytometer under a microscope. Conidiophores were observed from 2-day-old cultures of A. flavus strains on YES medium, cultured at $37^{\circ} \mathrm{C}$ for $2 \mathrm{~d}$ in the dark. After $2 \mathrm{~d}$, the plates were collected, and the spores and hyphae were scraped off the surface of the medium, making the mycelia visible. Mycelia were cut into short strips and placed on glass slides, which were in plates lined with moistened filter paper. The plates were then incubated at $37^{\circ} \mathrm{C}$ for $12 \mathrm{~h}$ under light conditions. The mycelia strips were viewed under a microscope to observe conidiophore formed. Sclerotia production was analyzed using a method previously described with a slight modification $[4,59]$. Concisely, $10^{6}$ spores of each strain were point-inoculated on GMM supplemented with $2 \%$ sorbitol and $10 \mathrm{mM}$ Gln as the nitrogen source and cultured at $37^{\circ} \mathrm{C}$ for $8 \mathrm{~d}$ in dark conditions. After $8 \mathrm{~d}$, the plates were sprayed with $75 \%$ ethanol to wash away conidia and expose sclerotia. The sclerotia produced on each plate were then counted.

\subsection{AF extraction and Analysis}

AF extraction was carried out from A. flavus liquid cultures in YES, PDB, and GMM supplemented with $50 \mathrm{mM}$ nitrogen sources, and analyzed using a previously described TLC (thin layer chromatography) method [63]. 


\subsection{Stress Assay}

PDA was supplemented with different stress agents, $\mathrm{NaCl}(0.5 \mathrm{M})$ and $\mathrm{KCl}(0.5 \mathrm{M})$ for osmotic stress, $\mathrm{H}_{2} \mathrm{O}_{2}(3 \mathrm{mM})$ for oxidative stress, Congo Red (CR, $\left.0.3 \mathrm{mg} / \mathrm{mL}\right)$, calcofluor white (CFW, $0.1 \mathrm{mg} / \mathrm{mL}$ ) and SDS $(0.1 \mathrm{mg} / \mathrm{mL})$ for cell wall stress. $10^{6}$ conidia of $A$. flavus was point-inoculated onto the various media and incubated at $37^{\circ} \mathrm{C}$ for $4 \mathrm{~d}$ in dark condition. Each strain had three repeats for every type of stress, and the experiments were repeated at least thrice [58].

\subsection{Pathogenicity Assay}

Peanut seeds were used to analyze the pathogenicity of the A. flavus strains by previously described methods $[4,64,65]$. The amount of conidia and aflatoxin production were analyzed using the same methods described above.

\subsection{Subcellular Localization}

The localization strain AreA::RFP, in which areA was tagged with RFP, was constructed using the homologous recombination method. The RFP gene was tagged to the end of the are $A$ gene, just before its stop codon, so that $R F P$ would be expressed alongside are $A$. A vector containing the are $A$ coding region, $R F P$, pyrG and the $3^{\prime}$ flanking sequence of are $A$ was constructed and transformed into SRRC1709 protoplasts. The fragments were amplified using the following primer pairs: AR-F/AR-R, RFP-F/RFP-R, pyrG-F/pyrG-R, and are A-BF/areA-BR for are A coding region, RFP, pyrG, and the $3^{\prime}$ flanking sequence of are $A$, respectively. The AreA::RFP strain was cultured in $1.5 \mathrm{~mL}$ EP tubes containing $500 \mu \mathrm{L}$ GMM, supplemented with different nitrogen sources, $50 \mathrm{mM}$ (Gln, Ala, Pro, and $\mathrm{NH}_{4}$ ), at $37^{\circ} \mathrm{C}$ for $16 \mathrm{~h}$, in a shaker. The medium was discarded from the tubes, and hyphae were crushed and washed with phosphate buffer saline (PBS) at least 3 times. Then, $1 \mathrm{mg} / \mathrm{mL}$ 4,6-diamidino-2-phenylindole (DAPI) was added to the tubes now containing PBS, and incubated on ice for $15 \mathrm{~min}$, away from light. Hyphae were picked onto glass slides and viewed under a confocal microscope.

\subsection{Quantitative Reverse Transcription Polymerase Chain Reaction}

Mycelia were harvested at $72 \mathrm{~h}$ post-inoculation on YES medium from all strains. Total RNA was extracted using TRIzol reagent (Biomarker Technologies, Beijing, China), and the first strand cDNA was synthesized using TransScript ${ }^{\circledR}$ One-Step gDNA Removal and cDNA Synthesis SuperMix (Transgen Biotech, Beijing, China). qRT-PCR was performed using the Pikoreal 96 Real-time PCR System (ThermoFisher Scientific, Waltham, MA, USA), with Pikoreal ${ }^{\mathrm{TM}} 2.2$ software (ThermoFisher Scientific, Waltham, MA, USA) and SYBR Green supermix (Takara, Beijing, China). The qRT-PCR conditions were as follows: $95^{\circ} \mathrm{C}$ for $7 \mathrm{~min}, 40$ cycles of $95^{\circ} \mathrm{C}$ for $5 \mathrm{~s}$, and $60^{\circ} \mathrm{C}$ for $30 \mathrm{~s}$. The $2^{-\Delta \Delta C T}$ method was used to calculate relative expression of transcripts [66]. The $\mathrm{Ct}$ values for actin and are $\mathrm{A}$ were obtained from all $A$. flavus strains, with WT as the control. The $\mathrm{Ct}$ values of actin obtained from the $A$. flavus strains were then subtracted from the $\mathrm{Ct}$ values of areA in the respective strains. The value of $\Delta \Delta C T$ was calculated from the resulting differences, and $2^{-\Delta \Delta C T}$ was then used to obtain the expression fold change. Actin was used as an internal control for the normalization of the expression data. All qRT-PCR primers were listed in Table 2.

\subsection{Statistical Analysis}

Data are presented as the mean \pm standard deviation (SD) of three biological replicate samples. Statistical and significance analysis were carried out using GraphPad Prism 5, and significance was recognized if $p$-values were $<0.05$. All results from the assays were differentiated by comparing the mutant strains ( $\triangle$ are $A$ and OE::are $A$ ) to the wild-type strain (WT) using one-way analysis of variance. 
Supervision, B.W. and S.W. (Shihua Wang); Writing-Original draft, O.E.F.; Writing—Review and editing, O.E.F., K.Y. and S.W. (Shihua Wang).

Funding: The research was supported by National Natural Science Foundation of China (No. 31772105) and Natural Science Foundation of Fujian Province, China (No. 2018J07002).

Acknowledgments: We thank Xiaoyun Han, Guang Yang and Xiuna Wang for their assistance and advice during the course of this study.

Conflicts of Interest: The authors declare no competing financial interests.

\section{References}

1. Cotty, P.J. Virulence and Cultural Characteristics of Two Aspergillus flavus Strains Pathogenic on Cotton. Phytopathology 1989, 79, 808-814. [CrossRef]

2. Michailides, T.; Thomidis, T. First report of Aspergillus flavus causing fruit rots of peaches in Greece. Plant Pathol. 2007, 56, 352. [CrossRef]

3. Klich, M.A. Aspergillus flavus: The major producer of aflatoxin. Mol. Plant Pathol. 2007, 8, 713-722. [CrossRef] [PubMed]

4. Geiser, D.M.; Timberlake, W.E.; Arnold, M.L. Loss of Meiosis in Aspergillus. Mol. Biol. Evol. 1996, $13,809-817$. [CrossRef]

5. Yu, J. Current understanding on aflatoxin biosynthesis and future perspective in reducing aflatoxin contamination. Toxins 2012, 4, 1024-1057. [CrossRef]

6. Amaike, S.; Keller, N.P. Aspergillus flavus. Annu. Rev. Phytopathol. 2011, 49, 107-133. [CrossRef]

7. Bai, Y.; Lan, F.; Yang, W.; Zhang, F.; Yang, K.; Li, Z.; Gao, P.; Wang, S. sRNA profiling in Aspergillus flavus reveals differentially expressed miRNA-like RNAs response to water activity and temperature. Fungal Genet. Biol. 2015, 81, 113-119. [CrossRef]

8. Zhang, F.; Guo, Z.; Zhong, H.; Wang, S.; Yang, W.; Liu, Y.; Wang, S. RNA-Seq-based transcriptome analysis of aflatoxigenic Aspergillus flavus in response to water activity. Toxins 2014, 6, 3187-3207. [CrossRef]

9. Zhang, F.; Zhong, H.; Han, X.; Guo, Z.; Yang, W.; Liu, Y.; Yang, K.; Zhuang, Z.; Wang, S. Proteomic profile of Aspergillus flavus in response to water activity. Fungal Biol. 2015, 119, 114-124. [CrossRef]

10. Agrios, G.N. Chapter eleven-Plant diseases caused by fungi. In Plant Pathology, 5th ed.; Agrios, G.N., Ed.; Academic Press: San Diego, CA, USA, 2005; pp. 385-614.

11. Marzluf, G.A. Genetic regulation of nitrogen metabolism in the fungi. Microbiol. Mol. Biol. Rev. 1997, 61, 17-32.

12. Wang, B.; Han, X.; Bai, Y.; Lin, Z.; Qiu, M.; Nie, X.; Wang, S.; Zhang, F.; Zhuang, Z.; Yuan, J.; et al. Effects of nitrogen metabolism on growth and aflatoxin biosynthesis in Aspergillus flavus. J. Hazard. Mater. 2017, 324, 691-700. [CrossRef] [PubMed]

13. Macios, M.; Caddick, M.X.; Weglenski, P.; Scazzocchio, C.; Dzikowska, A. The GATA factors AREA and AREB together with the co-repressor NMRA, negatively regulate arginine catabolism in Aspergillus nidulans in response to nitrogen and carbon source. Fungal Genet. Biol. 2012, 49, 189-198. [CrossRef] [PubMed]

14. Schonig, B.; Brown, D.W.; Oeser, B.; Tudzynski, B. Cross-species hybridization with Fusarium verticillioides microarrays reveals new insights into Fusarium fujikuroi nitrogen regulation and the role of AreA and NMR. Eukaryot. Cell 2008, 7, 1831-1846. [CrossRef] [PubMed]

15. Haas, H.; Marzluf, G.A. NRE, the major nitrogen regulatory protein of Penicillium chrysogenum, binds specifically to elements in the intergenic promoter regions of nitrate assimilation and penicillin biosynthetic gene clusters. Curr. Genet. 1995, 28, 177-183. [CrossRef] [PubMed]

16. Froeliger, E.H.; Carpenter, B.E.; Froeliger, E. NUT1, a major nitrogen regulatory gene in Magnaporthe grisea, is dispensable for pathogenicity. Mol. Gen. Genet. MGG 1996, 251, 647-656. [PubMed]

17. Xiao, X.; Marzluf, G.A. Identification of the native NIT2 major nitrogen regulatory protein in nuclear extracts of Neurospora crassa. Genetica 1996, 97, 153-163. [CrossRef]

18. Mihlan, M.; Homann, V.; Liu, T.W.; Tudzynski, B. AREA directly mediates nitrogen regulation of gibberellin biosynthesis in Gibberella fujikuroi, but its activity is not affected by NMR. Mol. Microbiol. 2003, 47, 975-991. [CrossRef] 
19. Ravagnani, A.; Gorfinkiel, L.; Langdon, T.; Diallinas, G.; Adjadj, E.; Demais, S.; Gorton, D.; Arst HN Jr Scazzocchio, C. Subtle hydrophobic interactions between the seventh residue of the zinc finger loop and the first base of an HGATAR sequence determine promoter-specific recognition by the Aspergillus nidulans GATA factor AreA. EMBO J. 1997, 16, 3974-3986. [CrossRef]

20. Xiao, X.; Fu, Y.H.; Marzluf, G. The Negative-Acting NMR Regulatory Protein of Neurospora crassa Binds to and Inhibits the DNA-Binding Activity of the Positive-Acting Nitrogen Regulatory Protein NIT2. Biochemistry 1995, 34, 8861-8868. [CrossRef]

21. Platt, A.; Langdon, T.; Arst HNJr Kirk, D.; Tollervey, D.; Sanchez, J.M.; Caddick, M.X. Nitrogen metabolite signalling involves the C-terminus and the GATA domain of the Aspergillus transcription factor AREA and the 3' untranslated region of its mRNA. EMBO J. 1996, 15, 2791-2801. [CrossRef]

22. Andrianopoulos, A.; Kourambas, S.; Sharp, J.A.; Davis, M.A.; Hynes, M.J. Characterization of the Aspergillus nidulans nmrA gene involved in nitrogen metabolite repression. J. Bacteriol. 1998, 180, 1973-1977. [PubMed]

23. Han, X.; Qiu, M.; Wang, B.; Yin, W.B.; Nie, X.; Qin, Q.; Ren, S.; Yang, K.; Zhang, F.; Zhuang, Z.; et al. Functional Analysis of the Nitrogen Metabolite Repression Regulator Gene nmrA in Aspergillus flavus. Front. Microbiol. 2016, 7, 1794. [CrossRef] [PubMed]

24. Lopez-Berges, M.S.; Schäfer, K.; Hera, C.; Di Pietro, A. Combinatorial function of velvet and AreA in transcriptional regulation of nitrate utilization and secondary metabolism. Fungal Genet. Biol. 2014, 62, 78-84. [CrossRef] [PubMed]

25. Crespo, J.L.; Hall, M.N. Elucidating TOR signaling and rapamycin action: Lessons from Saccharomyces cerevisiae. Microbiol. Mol. Biol. Rev. 2002, 66, 579-591. [CrossRef] [PubMed]

26. Hunter, C.C.; Siebert, K.S.; Downes, D.J.; Wong, K.H.; Kreutzberger, S.D.; Fraser, J.A.; Clarke, D.F.; Hynes, M.J.; Davis, M.A.; Todd, R.B. Multiple nuclear localization signals mediate nuclear localization of the GATA transcription factor AreA. Eukaryot. Cell 2014, 13, 527-538. [CrossRef]

27. Todd, R.B.; Fraser, J.A.; Wong, K.H.; Davis, M.A.; Hynes, M.J. Nuclear accumulation of the GATA factor AreA in response to complete nitrogen starvation by regulation of nuclear export. Eukaryot. Cell 2005, 4, 1646-1653. [CrossRef]

28. Li, J.; Pan, Y.; Liu, G. Disruption of the nitrogen regulatory gene AcareA in Acremonium chrysogenum leads to reduction of cephalosporin production and repression of nitrogen metabolism. Fungal Genet. Biol. 2013, 61, 69-79. [CrossRef]

29. Hou, R.; Jiang, C.; Zheng, Q.; Wang, C.; Xu, J.R. The AreA transcription factor mediates the regulation of deoxynivalenol (DON) synthesis by ammonium and cyclic adenosine monophosphate (cAMP) signalling in Fusarium graminearum. Mol. Plant Pathol. 2015, 16, 987-999. [CrossRef]

30. Haas, H.; Bauer, B.; Redl, B.; Stöffler, G.; Marzluf, G.A. Molecular cloning and analysis of nre, the major nitrogen regulatory gene of Penicillium chrysogenum. Curr. Genet. 1995, 27, 150-158. [CrossRef]

31. Kim, H.; Woloshuk, C.P. Role of AREA, a regulator of nitrogen metabolism, during colonization of maize kernels and fumonisin biosynthesis in Fusarium verticillioides. Fungal Genet. Biol. 2008, 45, 947-953. [CrossRef]

32. Michielse, C.B.; Pfannmüller, A.; Macios, M.; Rengers, P.; Dzikowska, A.; Tudzynski, B. The interplay between the GATA transcription factors AreA, the global nitrogen regulator and AreB in Fusarium fujikuroi. Mol. Microbiol. 2014, 91, 472-493. [CrossRef] [PubMed]

33. Tudzynski, B.; Homann, V.; Feng, B.; Marzluf, G.A. Isolation, characterization and disruption of the areA nitrogen regulatory gene of Gibberella fujikuroi. Mol. Gen. Genet. MGG 1999, 261, 106-114. [PubMed]

34. Bi, F.; Ment, D.; Luria, N.; Meng, X.; Prusky, D. Mutation of AREA affects growth, sporulation, nitrogen regulation, and pathogenicity in Colletotrichum gloeosporioides. Fungal Genet. Biol. 2017, 99, 29-39. [CrossRef] [PubMed]

35. Giese, H.; Sondergaard, T.E.; Sorensen, J.L. The AreA transcription factor in Fusarium graminearum regulates the use of some nonpreferred nitrogen sources and secondary metabolite production. Fungal Biol. 2013, 117, 814-821. [CrossRef] [PubMed]

36. Arst, H.N.; Cove, D.J. Nitrogen metabolite repression in Aspergillus nidulans. Mol. Gen. Genet. MGG 1973, 126, 111-141. [CrossRef] [PubMed]

37. Christensen, T.; Hynes, M.J.; Davis, M.A. Role of the Regulatory Gene areA of Aspergillus oryzae in Nitrogen Metabolism. Appl. Environ. Microbiol. 1998, 64, 3232-3237.

38. Park, H.-S.; Yu, J.-H. Genetic control of asexual sporulation in filamentous fungi. Curr. Opin. Microbiol. 2012, 15, 669-677. [CrossRef] 
39. Min, K.; Shin, Y.; Son, H.; Lee, J.; Kim, J.C.; Choi, G.J.; Lee, Y.W. Functional analyses of the nitrogen regulatory gene areA in Gibberella zeae. FEMS Microbiol. Lett. 2012, 334, 66-73. [CrossRef]

40. Tudzynski, B. Nitrogen regulation of fungal secondary metabolism in fungi. Front. Microbiol. 2014, 5, 656. [CrossRef]

41. Brakhage, A.A. Regulation of fungal secondary metabolism. Nat. Rev. Microbiol. 2012, 11, 21. [CrossRef]

42. Fox, E.M.; Howlett, B.J. Secondary metabolism: Regulation and role in fungal biology. Curr. Opin. Microbiol. 2008, 11, 481-487. [CrossRef] [PubMed]

43. Ehrlich, K.C.; Chang, P.-K.; Yu, J.; Cary, J.W.; Bhatnagar, D. Control of Aflatoxin Biosynthesis in Aspergilli. In Aflatoxins-Biochemistry and Molecular Biology; IntechOpen: London, UK, 2011; pp. 21-40.

44. Cary, J.W.; Ehrlich, K.C.; Kale, S.P.; Calvo, A.M.; Bhatnagar, D.; Cleveland, T.E. Regulatory elements in aflatoxin biosynthesis. Mycotoxin Res. 2006, 22, 105. [CrossRef] [PubMed]

45. Liu, B.-H.; Chu, F.S. Regulation of aflR and Its Product, AflR, Associated with Aflatoxin Biosynthesis. Appl. Environ. Microbiol. 1998, 64, 3718-3723. [PubMed]

46. Fasoyin, O.E.; Wang, B.; Qiu, M.; Han, X.; Chung, K.R.; Wang, S. Carbon catabolite repression gene creA regulates morphology, aflatoxin biosynthesis and virulence in Aspergillus flavus. Fungal Genet. Biol. 2018, 115, 41-51. [CrossRef] [PubMed]

47. Gonzalez, R.; Gavrias, V.; Gomez, D.; Scazzocchio, C.; Cubero, B. The integration of nitrogen and carbon catabolite repression in Aspergillus nidulans requires the GATA factor AreA and an additional positive-acting element, ADA. EMBO J. 1997, 16, 2937-2944. [CrossRef] [PubMed]

48. Duran, R.; Cary, J.W.; Calvo, A.M. Role of the osmotic stress regulatory pathway in morphogenesis and secondary metabolism in filamentous fungi. Toxins 2010, 2, 367-381. [CrossRef]

49. Mellersh, D.G.; Foulds, I.V.; Higgins, V.J.; Heath, M.C. $\mathrm{H}_{2} \mathrm{O}_{2}$ plays different roles in determining penetration failure in three diverse plant-fungal interactions. Plant J. 2002, 29, 257-268. [CrossRef]

50. Shetty, N.P.; Mehrabi, R.; Lütken, H.; Haldrup, A.; Kema, G.H.; Collinge, D.B.; Jørgensen, H.J. Role of hydrogen peroxide during the interaction between the hemibiotrophic fungal pathogen Septoria tritici and wheat. New Phytol. 2007, 174, 637-647. [CrossRef]

51. Veal, E.A.; Day, A.M.; Morgan, B.A. Hydrogen Peroxide Sensing and Signaling. Mol. Cell 2007, 26, 1-14. [CrossRef]

52. Lamb, C.; Dixon, R.A. The Oxidative Burst in Plant Disease Resistance. Annu. Rev. Plant Physiol. 1997, 48, 251-275. [CrossRef]

53. Wojtaszek, P. Oxidative burst: An early plant response to pathogen infection. Biochem. J. 1997, 322 Pt 3 , 681-692. [CrossRef]

54. Snoeijers, S.S.; Pérez-García, A.; Joosten, M.H.A.J.; De Wit, P.J.G.M. The Effect of Nitrogen on Disease Development and Gene Expression in Bacterial and Fungal Plant Pathogens. Eur. J. Plant Pathol. 2000, 106, 493-506. [CrossRef]

55. Proctor, R.H.; Hohn, T.M.; McCormick, S.P. Reduced virulence of Gibberella zeae caused by disruption of a trichothecene toxin biosynthetic gene. Mol. Plant-Microbe Interact. 1995, 8, 593-601.

56. An, Z.; Mei, B.; Yuan, W.M.; Leong, S.A. The distal GATA sequences of the sid1 promoter of Ustilago maydis mediate iron repression of siderophore production and interact directly with Urbs1, a GATA family transcription factor. EMBO J. 1997, 16, 1742-1750. [CrossRef] [PubMed]

57. Whiteside, S.T.; Goodbourn, S. Signal transduction and nuclear targeting: Regulation of transcription factor activity by subcellular localization. J. Cell Sci. 1993, 104, 949-955. [PubMed]

58. Yang, K.; Liang, L.; Ran, F.; Liu, Y.; Li, Z.; Lan, H.; Gao, P.; Zhuang, Z.; Zhang, F.; Nie, X.; et al. The DmtA methyltransferase contributes to Aspergillus flavus conidiation, sclerotial production, aflatoxin biosynthesis and virulence. Sci. Rep. 2016, 6, 232-259. [CrossRef] [PubMed]

59. Payne, G.A.; Brown, M.P. Genetics and Physiology of Aflatoxin Biosynthesis. Annu. Rev. Phytopathol. 1998, 36, 329-362. [CrossRef] [PubMed]

60. Chang, P.K.; Scharfenstein, L.L.; Wei, Q.; Bhatnagar, D. Development and refinement of a high-efficiency gene-targeting system for Aspergillus flavus. J. Microbiol. Methods 2010, 81, 240-246. [CrossRef]

61. Tamura, K.; Peterson, D.; Peterson, N.; Stecher, G.; Nei, M.; Kumar, S. MEGA5: molecular evolutionary genetics analysis using maximum likelihood, evolutionary distance, and maximum parsimony methods. Mol. Biol. Evol. 2011, 28, 2731-2739. [CrossRef] 
62. Yu, J.; Chang, P.K.; Ehrlich, K.C.; Cary, J.W.; Bhatnagar, D.; Cleveland, T.E.; Payne, G.A.; Linz, J.E.; Woloshuk, C.P.; Bennett, J.W. Clustered pathway genes in aflatoxin biosynthesis. Appl. Environ. Microbiol. 2004, 70, 1253-1262. [CrossRef]

63. Bennett, J.W.; Papa, K.E. The Aflatoxigenic Aspergillus SPP. In Advances in Plant Pathology; Sidhu, G.S., Ed.; Academic Press: San Diego, CA, USA, 1988; pp. 263-280.

64. Kale, S.P.; Cary, J.W.; Bhatnagar, D.; Bennett, J.W. Characterization of experimentally induced, nonaflatoxigenic variant strains of Aspergillus parasiticus. Appl. Environ. Microbiol. 1996, 62, 3399-3404.

65. Georgianna, D.R.; Payne, G.A. Genetic regulation of aflatoxin biosynthesis: From gene to genome. Fungal Genet. Biol. 2009, 46, 113-125. [CrossRef] [PubMed]

66. Chang, P.K.; Cary, J.W.; Bhatnagar, D.; Cleveland, T.E.; Bennett, J.W.; Linz, J.E.; Woloshuk, C.P.; Payne, G.A. Cloning of the Aspergillus parasiticus apa-2 gene associated with the regulation of aflatoxin biosynthesis. Appl. Environ. Microbiol. 1993, 59, 3273-3279. [PubMed]

(C) 2019 by the authors. Licensee MDPI, Basel, Switzerland. This article is an open access article distributed under the terms and conditions of the Creative Commons Attribution (CC BY) license (http://creativecommons.org/licenses/by/4.0/). 